\title{
Frozen green beans (Phaseolus vulgaris, L.) quality profile evaluation during home storage
}

\author{
R.C. Martins, C.L.M. Silva * \\ Escola Superior de Biotecnologia, Universidade Católica Portuguesa, Rua Dr. António Bernardino de Almeida, 4200-072 Porto, Portugal
}

Keywords: Frozen green beans; Quality retention; Home storage simulation

\begin{abstract}
Home storage is at the end of the frozen foods distribution chain, and not much is known how it affects frozen vegetables quality. This research presents a computational evaluation of frozen green beans (Phaseolus vulgaris, L.) quality profile, in terms of ascorbic acid, starch content, chlorophylls $a$ and $b$, colour (Hunter $a$ and $b$ co-ordinates and total colour difference) and flavour, at storage temperatures of $+5,-6,-12$ and $-18{ }^{\circ} \mathrm{C}$, for respectively, $1,4,14$, and 60 days. Simulations were set to access the impact of the preestablished after sale dates of the 'star dating' system.

Results demonstrate that green beans nutritional and sensory parameters are well retained at the storage temperatures of $+5,-6$ and $-12{ }^{\circ} \mathrm{C}$. At $-18{ }^{\circ} \mathrm{C}$, sensory parameters (e.g. colour and flavour) are well retained, but nutritional parameters, such as ascorbic acid and starch, degraded. The study concluded that the 'star dating' system is a good after sale dating system for frozen green beans for the storage temperatures of $+5,-6$ and $-12{ }^{\circ} \mathrm{C}$. The system fails to maintain a good balance between sensory and nutritional parameters at low storage temperatures (e.g. $\left.<-18{ }^{\circ} \mathrm{C}\right)$.
\end{abstract}

\section{Introduction}

Green beans (Phaseolus vulgaris, L.) are one of the most important vegetables produced in Portugal. These are well known for their high quality, both in nutritional (e.g. vitamins, fibers and starch) and sensory properties (e.g. colour, texture and flavour). Green beans are mostly grown outdoors and harvested seasonally, which makes freezing a very important process preservation for extending their availability throughout the year.

Shelf-life of frozen green beans has been normally established by sensory panels. Most dating philosophies do not rely on the study of nutritional attributes that, in some situations, may limit the shelf-life. Thus, shelf-life should rely on a quality profile evaluation, that takes into account both nutritional and sensory parameters. Some dating philosophies are described as follows: (i)

${ }^{*}$ Corresponding author. Tel.: +351-22-5580058; fax: +351-225090351.

E-mail addresses: r.m.c.m@clix.pt (R.C. Martins), crislui@esb. ucp.pt (C.L.M. Silva). just noticeable difference (JND), when differences are just detected between a test and a control sample; (ii) practical storage life (PSL), which is considered as the storage time where frozen vegetables are still acceptable to the consumer; and (iii) high quality life (HQL), which has been defined as the storage time when $70 \%$ of the sensory panel is able to detect a different sample in a triangle test (Labuza, 1982).

The quality loss kinetics of green beans has been studied at storage temperatures of $-7,-15$ and $-30{ }^{\circ} \mathrm{C}$ (Martins, 2003). Parameters, such as ascorbic acid (AA), total vitamin $\mathrm{C}$ (ascorbic acid+dehydro-ascorbic acid (DHAA)), starch, reducing sugars, texture, chlorophylls $a$ and $b$ and colour (Hunter $a$ and $b$ coordinates and total colour difference- $-T C D_{\mathrm{H}}$ ), have been shown to be sensitive during frozen storage (Martins \& Silva, 2002, 2003), as well as flavour retention (Labuza, 1982).

Quality loss kinetics were mostly modeled by firstorder (Eq. (1)) and fractional conversion (Eq. (2)) kinetics (Martins \& Silva, 2002, 2003):

$$
c=c_{0} \cdot \exp \left(-k_{\mathrm{ref}} \cdot \exp \left[-\frac{E a}{R} \cdot\left(\frac{1}{T}-\frac{1}{T_{\mathrm{ref}}}\right)\right] \cdot t\right)
$$




\begin{tabular}{|llll|}
\hline \multicolumn{2}{|l|}{ Nomenclature } & \\
$\lambda$ & thermal conductivity $\left(\mathrm{W} \mathrm{m}^{-1} \mathrm{~K}^{-1}\right)$ & $\mathrm{JND}$ & just noticeable difference \\
$\rho$ & density $\left(\mathrm{kg} \mathrm{m}^{-3}\right)$ & $\mathrm{PSL}$ & practical storage life \\
$c$ & quality retention $(\%)$ at time $t$ & $\mathrm{TCD}$ & total colour difference \\
$C p$ & thermal capacity $\left(\mathrm{J} \mathrm{kg}^{-1} \mathrm{~K}^{-1}\right)$ & Subscripts \\
$E a$ & Arrhenius activation energy $\left(\mathrm{J} \mathrm{mol}^{-1}\right)$ & 0 & refers to initial condition \\
$h$ & surface heat transfer coefficient $\left(\mathrm{W} \mathrm{m}^{-2} \mathrm{~K}^{-1}\right)$ & air & refers to air \\
$k$ & kinetic rate $\left(\mathrm{day}^{-1}\right)$ & $\mathrm{eq}$ & refers to equilibrium \\
$R$ & universal gas constant $\left(\mathrm{J} \mathrm{mol}^{-1} \mathrm{~K}^{-1}\right)$ & $\mathrm{f}$ & refers to frozen \\
$T$ & temperature $\left({ }^{\circ} \mathrm{C}\right.$ or $\left.\mathrm{K}\right)$ & $\mathrm{gb}$ & refers to green beans \\
$t$ & time (days) & $\mathrm{H}$ & refers to Hunter \\
$x$ & packaging film thickness $(m)$ & $\mathrm{m}$ & refers to melting \\
Abbreviations & $\mathrm{p}$ & refers to packaging material \\
AA $\quad$ ascorbic acid & ref & refers to reference temperature \\
DHAA dehydro-ascorbic acid & $\mathrm{w}$ & refers to water \\
HQL high quality life & & \\
\hline
\end{tabular}

$\frac{c-c_{\mathrm{eq}}}{c_{0}-c_{\mathrm{eq}}}=\exp \left(-k_{\mathrm{ref}} \cdot \exp \left[-\frac{E a}{R} \cdot\left(\frac{1}{T}-\frac{1}{T_{\text {ref }}}\right)\right] \cdot t\right)$

where $c$ is the quality retention (\%) at time $t, c_{0}$ the initial quality retention (\%), $c_{\text {eq }}$ the equilibrium quality retention ( $\%), k_{\text {ref }}$ the kinetic rate $\left(\mathrm{day}^{-1}\right)$ at the reference temperature, $T_{\text {ref }}(K), E a$ the Arrhenius activation energy $\left(\mathrm{J} \mathrm{mol}^{-1}\right), R$ the universal gas constant $\left(\mathrm{J} \mathrm{mol}^{-1} \mathrm{~K}^{-1}\right)$ and $T$ the temperature $(K)$. Quality loss kinetic parameters are presented in Table 1.

Vitamin $\mathrm{C}$ is an important anti-oxidant in the human body, that can prevent cancer (Byers \& Perry, 1992). Ascorbic acid (AA) degradation inside green beans occurs due to oxidation to dehydro-ascorbic acid (DHAA), which still retains vitamin $\mathrm{C}$ activity, and has been shown to be generally more stable than AA, at low temperatures. Vitamin C losses occur when DHAA is oxidised to 2,3-diketo-L-gulonic acid. Molecular oxygen is a quiet mobile molecule at low temperatures, and its solubility increases at refrigeration temperatures. Therefore, AA oxidation to DHAA is a reaction with low Ea (Martins \& Silva, 2002). Due to its sensitivity, vitamin $\mathrm{C}$ has been considered a good indicator of nutritional quality of water soluble vitamins (such as the B complex) in frozen vegetables.

Acid catalysed reactions are responsible for quality losses during frozen storage, due to an increase in $\mathrm{H}^{+}$ concentration. This mostly affects colour, texture and flavour. Texture losses occur by softening processes, which are related to the hydrolisis of structural sugars, such as the decrease in pectin content (Alonso, Canet, \& Rodrigez, 1997; Fuchigami, Hyakumoto, \& MiYazaki, 1995) and the downshift in weight of hemicelluloses (Jackman \& Stanley, 1995) by acid catalysed hydrolysis.

Table 1

Green beans quality loss kinetic parameters

\begin{tabular}{|c|c|c|c|c|}
\hline Quality parameter & $c_{0}$ & $c_{\text {eq }}$ & $k_{\mathrm{ref}^{\mathrm{a}}}\left(\mathrm{day}^{-1}\right)$ & $E a\left(\mathrm{~kJ} \mathrm{~mol}^{-1}\right)$ \\
\hline Ascorbic acid (mg $\left.100 \mathrm{~g}^{-1}\right)$ & 146.1 & - & $15.61 \times 10^{-2}$ & 3.86 \\
\hline Vitamin C $\left(\mathrm{mg} 100 \mathrm{~g}^{-1}\right)$ & 146.1 & - & $3.226 \times 10^{-2}$ & 42.01 \\
\hline Chlorophyll $a\left(\mathrm{mg} \mathrm{g}^{-1}\right)$ & $4.559 \times 10^{-2}$ & - & $4.793 \times 10^{-2}$ & 48.73 \\
\hline Chlorophyll $b\left(\mathrm{mg} \mathrm{g}^{-1}\right)$ & $2.572 \times 10^{-2}$ & - & $4.795 \times 10^{-2}$ & 49.60 \\
\hline$a$-value & -11.931 & -6.329 & $6.600 \times 10^{-3}$ & 103.05 \\
\hline$b$-value & 13.099 & 10.101 & $22.189 \times 10^{-3}$ & 55.33 \\
\hline$T C D_{\mathrm{H}}$ & 3.745 & 7.486 & $5.999 \times 10^{-3}$ & 106.27 \\
\hline Starch $\left(\mathrm{g} 100 \mathrm{~g}^{-1}\right)$ & 8.211 & - & $9.896 \times 10^{-2}$ & 12.33 \\
\hline Stress $(\mathrm{MPa})$ & 2.453 & 1.237 & $3.828 \times 10^{-2}$ & 7.11 \\
\hline Flavour $^{\mathrm{b}}(\%)$ & 100 & - & $7.769 \times 10^{-2}$ & 117.00 \\
\hline
\end{tabular}

${ }^{\mathrm{a}} T_{\text {ref }}=-15^{\circ} \mathrm{C}$

${ }^{\mathrm{b}}$ Data from (Labuza, 1982). 
The downshift in hemicellulose is also considered a nutritional loss. Starch is also subjected to hydrolysis, and it has also been considered as good quality shelf-life indicator for frozen green beans (Moharram \& Rofael, 1993). Starch hydrolysis increases green bean sweetness, due to the release of glucose, contributing to both flavour and texture degradation.

Colour loss of green vegetables, such as green beans during frozen storage, is mainly attributed to the fading of the vivid green to an olive brown colour, due to chlorophyll's pheophytisation, by the replacement of chlorophyll magnesium by hydrogen (Dietrich, Boogs, Nutting, \& Weinstein, 1960; Heaton, Lencki, \& Maragoni, 1996; Schwartz \& Von Elbe, 1983). Colour has been shown to be stable at low temperatures (e.g. $\left.T<-18{ }^{\circ} \mathrm{C}\right)$. At this temperature metal-chlorophyll compounds, such as cupric-chlorophyll, retain a vivid green colour (e.g. the same effect is obtained with zinc complexes, such as the bright green colour of canned peas).

Acid catalysed reactions have also low activation energy (Ea) values in frozen green beans: (i) starch $\left(12.331 \pm 1.204 \mathrm{~kJ} \mathrm{~mol}^{-1}\right)$; (ii) texture $(7.114 \pm 3.611$ $\left.\mathrm{kJ} \mathrm{mol}^{-1}\right)$; and (iii) chlorophyll $a(48.730 \pm 1.273$ $\left.\mathrm{kJ} \mathrm{mol}^{-1}\right)$. Colour $\left(T C D_{\mathrm{H}}\right)$ and flavour retention are, however, high $E a$ quality loss reactions (respectively $106.272 \pm 1.049 \mathrm{~kJ} \mathrm{~mol}^{-1}$ and $117 \mathrm{~kJ} \mathrm{~mol}^{-1}$, for frozen green beans; see Table 1).

Shelf-life dating is a complex problem, where the quality profile should be evaluated over time, to give a global perspective on quality losses. Thus, dating should not be solely taken in terms of sensory attributes, but also in nutritional terms. Consumer acceptability does not yet reflect nutritional quality, however, consumer awareness on nutritional advantages of frozen vegetables makes a requirement for well balanced nutritional and sensory quality retention, which should be taken into account during estimation of the recommended shelf-life date. There is no standard criteria to determine the practical storage life (PQL) and high quality life (HQL). Quality retentions near $c_{0}$ correspond to a high quality standard, whereas residual values, such as near $c_{\text {eq }}$ or at infinite storage times, are characteristic of a low quality frozen stored green beans.

The main motivation of this research was to evaluate, by computer simulation, the green beans quality profile during frozen storage, in order to:

I. Determine how the quality profile evolves with time, at the different storage temperatures.

II. Determine quality profiles and shelf-life limiting factors, so that standard storage times can be derived.

III. Evaluate how the actual 'star marking' system recommended dates affect the quality profile.

IV. Derive possible HQL and PQL, based on simulation data.

\section{Materials and methods}

\section{Computational simulation}

Simulations were made using a computational system (described in Martins (2003)). The finite element method (FEM) (Braess, 1997; Segerlind, 1984) was used to model heat transfer with phase transition and calculate the quality losses across a $900 \mathrm{~g}$ of frozen green beans package physical domain, presented in Fig. 1.

Heat is assumed to be transferred by conduction inside the package and by convection at the surface. The air thermal properties were considered constant over all simulations ( $\rho_{\text {air }}=1.18 \mathrm{~kg} \mathrm{~m}^{-3}, C p_{\text {air }}=1004 \mathrm{~J} \mathrm{~kg}^{-1} \mathrm{~K}^{-1}$, $\left.\lambda_{\text {air }}=0.08 \mathrm{~W} \mathrm{~m}^{-1} \mathrm{~K}^{-1}\right)$.

Green beans thermal conductivity $\left(\lambda_{\mathrm{gb}}\right)$ and thermal capacity $\left(C p_{\mathrm{gb}}\right)$ were described by a linear model above the melting point temperature $\left(T_{\mathrm{m}}\right)$. Below $T_{\mathrm{m}}$, thermal conductity was described by the Schwartzberg equation (Eq. (3)) (Schwartzberg, 1976), and the thermal capacity by the modified Schwartzberg equation (Eq. (4)) (Ramaswamy \& Tung, 1981):

$\lambda_{\mathrm{gb}}=\lambda_{\mathrm{f}}+\left(\lambda_{\mathrm{m}}-\lambda_{\mathrm{f}}\right) \cdot \frac{\left(T-T_{\mathrm{m}}\right)}{\left(T_{\mathrm{w}}-T_{\mathrm{m}}\right)^{2}}$

where $\lambda_{\mathrm{f}}$ and $\lambda_{\mathrm{m}}$ are, respectively, the thermal conductivities of green beans completely frozen and at the melting point temperature $\left(T_{\mathrm{m}}\right) . T_{\mathrm{w}}$ is the melting point temperature of pure water.

$C p_{\mathrm{gb}}=a+b T+\frac{c}{(d-T)^{2}}$

where $a, b, c$ and $d$ are the modified Schwarzberg equation constants.

Quality loss calculations were performed applying the kinetics equations (1) and (2), using the consistent formulation, to the green beans inside the package FEM mesh, presented on Fig. 1 (Martins, 2003). Kinetic parameters are presented in Table 1.

The temperature cycles of normal refrigerators was considered a stable limit cycle (Tong, 1994; Martins,

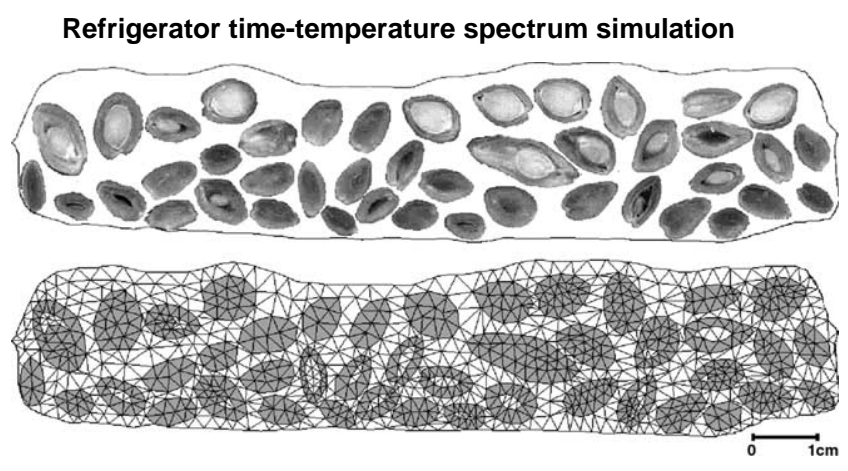

Fig. 1. Axial cut to a frozen green beans package and its FEM mesh. 
2003), where temperature is a well defined periodic oscillation, fluctuating around a central area on a phase diagram (Tong, 1994). Such behaviour was described in two phases: (i) when the compressor is turned on; and (ii) when the compressor is turned off. For each phase, the refrigerator dynamics is described by a linear stochastic differential equation, where the constants are different for each thermostat set point temperature. The thermostat triggers the compressor on, if the temperature exceeds its maximum limit, and off, once the minimum limit is attained.

\section{Quality retention profile}

The quality retention profile was studied for the 'star marking' after sales dating system. Storage temperature and recommended storage times are presented in Table 2. The average quality retentions were calculated for each storage temperature and time, using the 29 cases of a Box-Behnken factorial design (Montegomery, 1991), with the following factors: (i) initial temperature, $T_{0}$ $\left({ }^{\circ} \mathrm{C}\right)$; (ii) surface heat transfer coefficient, $h\left(\mathrm{~W} \mathrm{~m}^{-2} \mathrm{~K}^{-1}\right)$; (iii) packaging thermal conductivity, $\lambda_{\mathrm{p}}\left(\mathrm{W} \mathrm{m}^{-1} \mathrm{~K}^{-1}\right)$ and (iv) packaging film thickness, $x_{\mathrm{p}}(m)$. Maximum and minimum limits, of the factors, are presented in Table 3.

Quality retention data was sampled heuristically at: (i) $+5{ }^{\circ} \mathrm{C}: 8,16$ and $24 \mathrm{~h}$, (ii) $-6^{\circ} \mathrm{C}: 1,2,3$ and 4 days; (iii) $-12^{\circ} \mathrm{C}: 5,10$ and 14 days; and (iv) $-18{ }^{\circ} \mathrm{C}: 15,30,45$ and 60 days. The maximum and minimum average quality retentions at each time and temperature where identified.

The quality profile gives a global perspective on green beans quality degradation during home storage. The calculated values were used to analyse the suggested storage times, for a good balance between sensory and

Table 2

Frozen foods star marking system

\begin{tabular}{lll}
\hline Star code & $\begin{array}{l}\text { Average } \\
\text { temperature }\left({ }^{\circ}\right)\end{array}$ & $\begin{array}{l}\text { Remaining shelf-life inside } \\
\text { the refrigerator (day) }\end{array}$ \\
\hline Refrigerator & +5 & 1 \\
$*$ & -6 & 4 \\
$* *$ & -12 & 14 \\
$* * *$ & -18 & 60 \\
\hline
\end{tabular}

Table 3

Response surface design: factors and factor levels

\begin{tabular}{lll}
\hline Factor & Level & \\
\cline { 2 - 3 } & Min & Max \\
\hline Initial temperature $\left({ }^{\circ} \mathrm{C}\right)$ & -30 & -5 \\
Surface heat transfer & & \\
Coefficient $\left(\mathrm{W} \mathrm{m}^{-2} \mathrm{~K}^{-1}\right)$ & 6 & 12 \\
Thermal conductivity $\left(\mathrm{W} \mathrm{m}^{-1} \mathrm{~K}^{-1}\right)$ & 0.02 & 0.15 \\
Packaging film thickness $(\mathrm{m})$ & 0.0002 & 0.003 \\
\hline
\end{tabular}

nutritional parameters at the different storage temperatures. The balance between sensory and nutritional parameters retention was also used to propose new criteria for determining the practical quality life (PQL) and high quality life (HQL) of frozen green beans.

\section{Results and discussion}

\section{Quality losses at $+5 \stackrel{\circ}{\circ} \mathrm{C}$}

Fig. 2 presents the quality profile of a green beans package stored at $+5{ }^{\circ} \mathrm{C}$, inside a refrigerator, for 8,16 and $24 \mathrm{~h}$. It is possible to observe that average retention is, in general, good for all the simulated parameters.

Excellent retention is obtained in terms of AA (83.81\%), total vitamin C $(88.11 \%)$, starch $(86.21 \%)$, chlorophylls $a$ and $b(79.31 \%$ and $79.08 \%$, respectively), colour ( $a$-value $91.53 \%, b$-value $97.11 \%$ and $T C D_{\mathrm{H}}$ increase by $18.22 \%$ ) and texture $(97.68 \%)$ at $24 \mathrm{~h}$ of storage.

Flavour retention is low (12.3\%). Flavour is, in this case, the limiting quality parameter at $+5{ }^{\circ} \mathrm{C}$. Green beans exhibit high nutritional quality, colour and texture, but the sensory panel tends to give low values of flavour retention, after the first $8 \mathrm{~h}$ of storage.

Despite the Hunter $a$ and $b$ values showing only small variations, colour differences are perceptible between green beans. $T C D_{\mathrm{H}}$ values are higher than 3 , since the first measurement. Therefore, a sensory panel would find differences between green beans colour, even at the start of the simulation (TCD $>3$, difference very distinct; $1.5<\mathrm{TCD}<3$, difference distinct; and $\mathrm{TCD}<1.5$ small difference (DrLange, 1994; DrLange, 1999)). Note that, at this storage temperature, colour differences correspond to very small differences in Chlorophylls $a$ and $b$ contents (see Fig. 2).

Results also show that texture is not severely affected at this temperature over $24 \mathrm{~h}(97.68 \%)$. Such a result is in agreement with the high starch retention of $86.21 \%$. Thus, a small increase in sweetness is expected, due to an increase in glucose content.

The quality profile of Fig. 2 is considered good in terms of nutritional and sensory parameters during the recommended 'star marking' shelf-life dating. Simulation results reassure that, once frozen green beans are distributed under proper storage temperatures and for short periods of time, consumers will have high quality frozen green beans inside the $+5{ }^{\circ} \mathrm{C}$ refrigerator compartment for $24 \mathrm{~h}$. At this storage temperature, the star system shelf-life dating is good both in terms of sensory and nutritional attributes.

High quality is limited by flavour retention. High flavour retentions are obtained before the $8 \mathrm{~h}$ of defrost. Under these circumstances it is preferable to consume frozen green beans stored at $+5{ }^{\circ} \mathrm{C}$, before $16 \mathrm{~h}$ of 


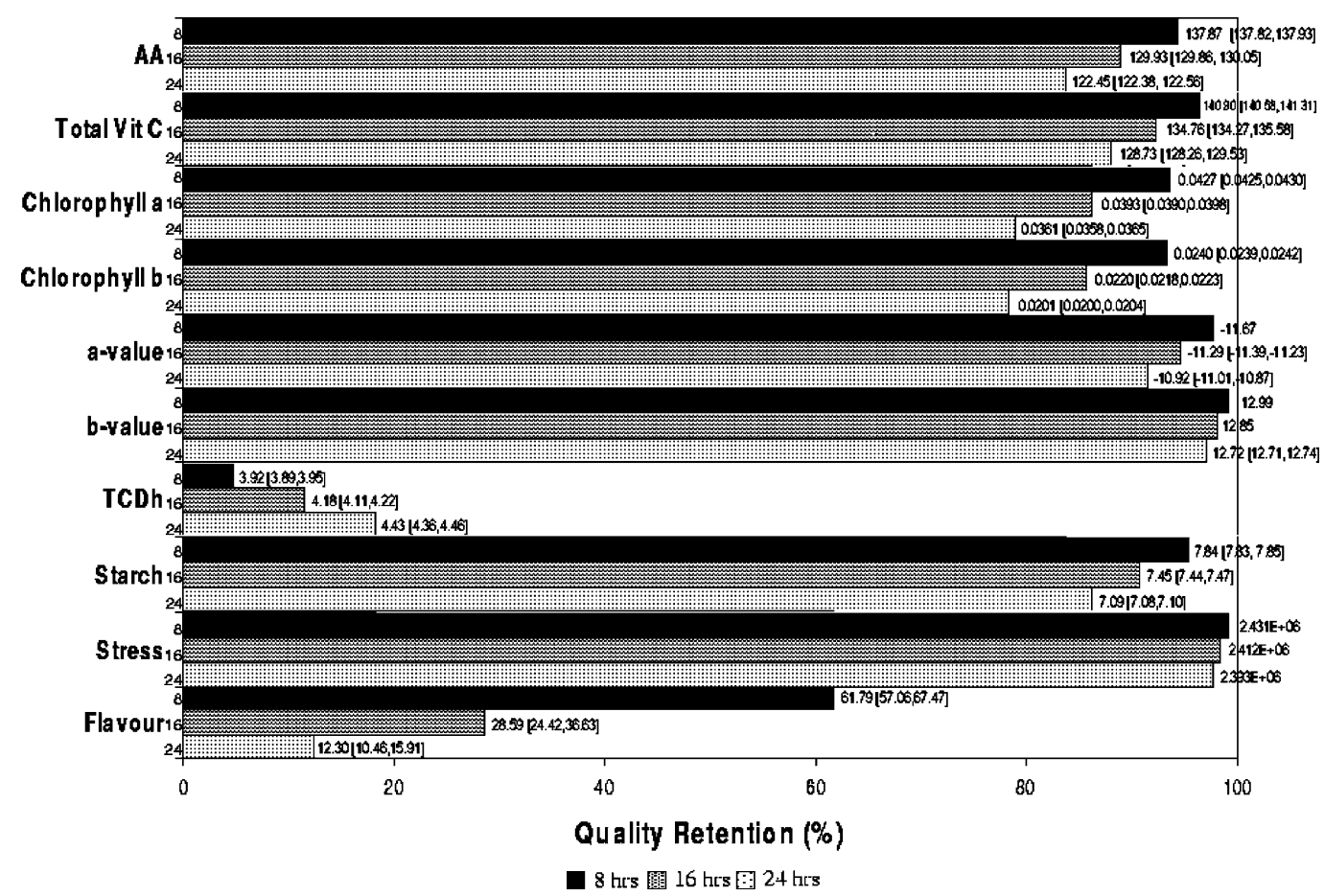

Fig. 2. Green beans quality retention (\%) profile, for 8,16 and $24 \mathrm{~h}$ of storage at $+5{ }^{\circ} \mathrm{C}$. Maximum and minimum limits of the quality parameter average retentions are indicated between brackets, if a significant difference is registered.

storage, and $24 \mathrm{~h}$ should be always the maximum storage time at this temperature, due to flavour retention limitations and microbiological growth.

\section{Quality losses at $-6{ }^{\circ} \mathrm{C}$}

Fig. 3 presents the average quality retention inside a refrigerator with a thermostat set point of $-6^{\circ} \mathrm{C}$, at 1,2 , 3 and 4 days of storage.

Fig. 3 shows significant AA losses at $-6{ }^{\circ} \mathrm{C}$, where at the fourth day of storage AA content is $51.47 \%$ of its initial value (see Table 1). The degradation of DHAA occurs at a moderate rate, where the total vitamin $\mathrm{C}$ content (AA+DHAA) remains at $77.53 \%$.

Starch also exhibits a significant degradation. At the 4 th day of storage, starch attained $61.64 \%$ of the initial value (see Table 1). Such significant reduction is reflected in the increase of reducing sugars content (glucose) and texture loss, where stress at the failure point is reduced to $92.21 \%$ of its initial value.

Significant Chlorophylls $a$ and $b$ losses occur at -6 ${ }^{\circ} \mathrm{C}$. Chlorophylls $a$ and $b$ content decrease to $65.59 \%$ and $65.04 \%$, respectively, at the fourth day of storage. Such a decrease is not directly observed in terms of colour Hunter $a$ and $b$ co-ordinates, which only shows reductions to $93.83 \%$ and $95.53 \%$, respectively. The $T C D_{\mathrm{H}}$ values increased on average $12.62 \%$.

Flavour retention is higher than at $+5{ }^{\circ} \mathrm{C}$, during the recommended maximum storage time. At the fourth day of storage, green beans retained $30.33 \%$ of the original flavour. Despite nutritional parameters are sensitive during the 4 days of recommended storage, flavour is still the most sensitive parameter, which limits shelf-life at $-6{ }^{\circ} \mathrm{C}$.

The 4 days of recommended storage at $-6{ }^{\circ} \mathrm{C}$ are capable of maintaining high nutritional and sensory standards, except for flavour retention. Very high quality is obtained both in nutritional and sensory parameters during the first 2 days of storage. Due to flavour degradation, green beans are preferably consumed before 3 days of storage. The fourth day marks the end of shelf-life in terms of flavour, but, nevertheless, green beans present good levels of vitamin C, starch, colour and texture.

\section{Quality losses at $-12 \stackrel{\circ}{\circ} \mathrm{C}$}

Fig. 4 presents the quality profile at $-12{ }^{\circ} \mathrm{C}$, during 5 , 10 and 14 days of storage.

Very significant losses occur to the AA content, during the recommended maximum storage time at -12 ${ }^{\circ} \mathrm{C}$ (see Fig. 4). AA content decreases very rapidly during the first 5 days of storage to $45.03 \%$, and at the 14th day attains a residual value of $10.72 \%$. During this period, almost all AA is converted to DHAA, which still retains vitamin $\mathrm{C}$ activity. Thus, the total vitamin $\mathrm{C}$ content is still well retained over the 14 days, where green beans exhibit $56.47 \%$ retention.

Starch degradation is also significant. After 5 days of storage, starch content decreases to $58.78 \%$ and at the 


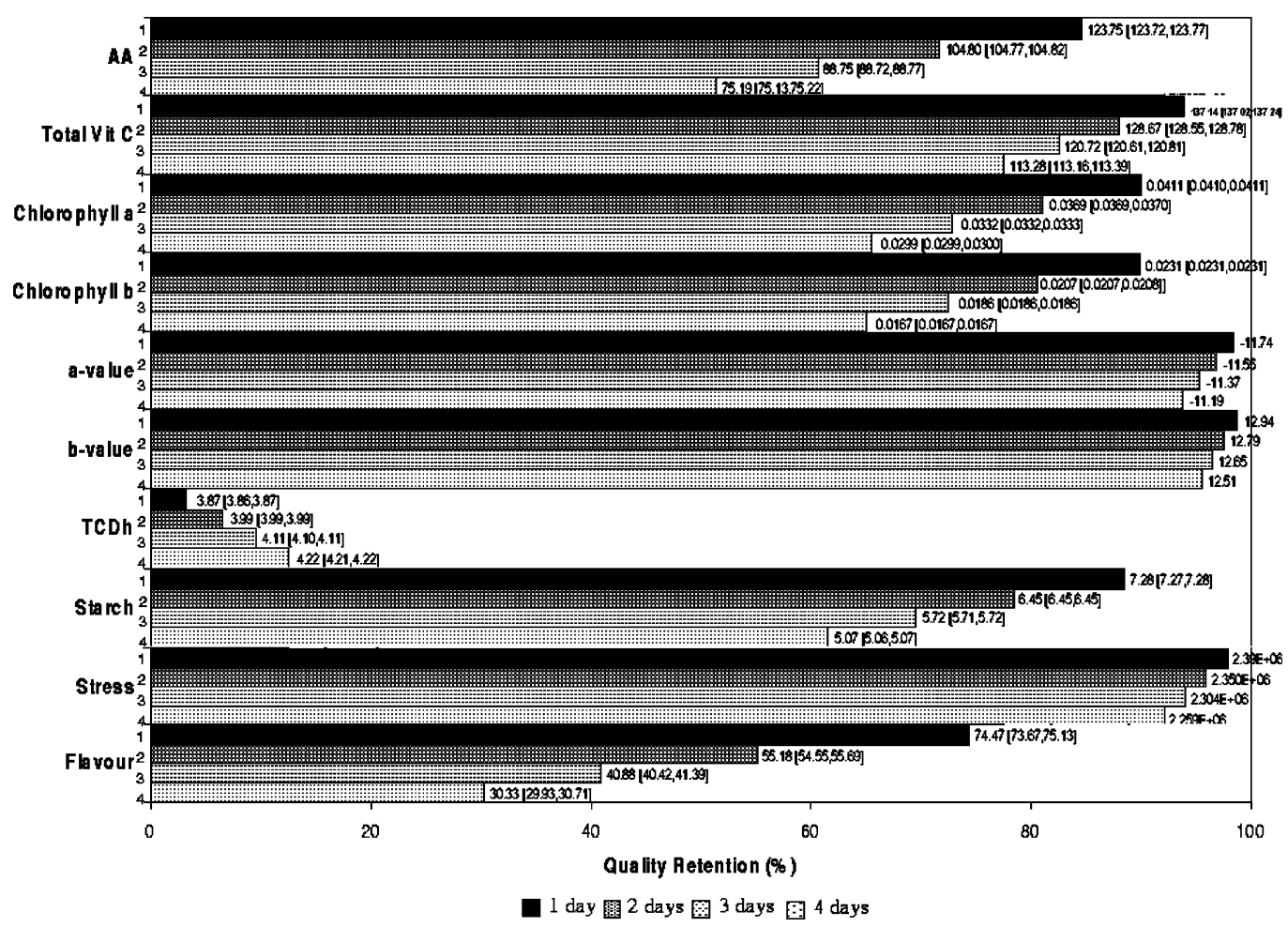

Fig. 3. Green beans quality retention (\%) profile, for $1,2,3$ and 4 days of storage at $-6{ }^{\circ} \mathrm{C}$. Maximum and minimum limits of the quality parameter average retentions are indicated between brackets, if a significant difference is registered.

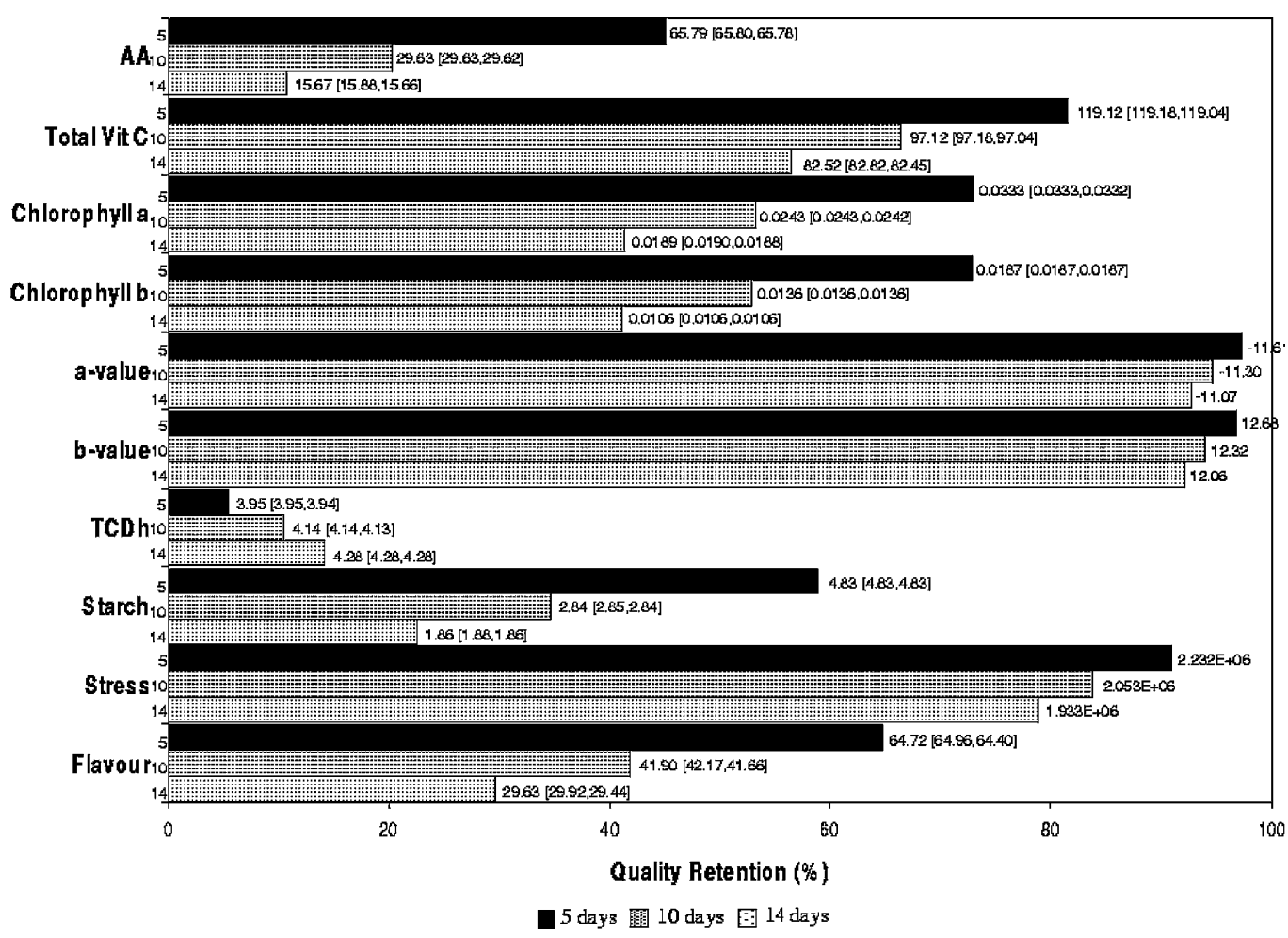

Fig. 4. Green beans quality retention (\%) profile, for 5, 10 and 14 days of storage at $-12{ }^{\circ} \mathrm{C}$. Maximum and minimum limits of the quality parameter average retentions are indicated between brackets, if a significant difference is registered. 
14th day it attains $22.66 \%$, corresponding to an increase in the reducing sugars content and softness. Thus, stress at the failure point decreases to $78.9 \%$ of its initial value, which is significant for a fractional conversion kinetics.

Chlorophylls $a$ and $b$ average retention at $-12{ }^{\circ} \mathrm{C}$ are, respectively, $41.39 \%$ and $41.13 \%$, after 14 days of storage. Although chlorophylls are degradated at low temperatures, colour is preserved. Such a result was expected from previous experimental results Martins and Silva (2002). One possible explanation for such phenomena is the formation of metal-chlorophyll compounds (copper or zinc), which retain a stable green colour at low temperatures. Colour retention was $92.80 \%$ and $92.09 \%$ for the Hunter $a$ and $b$ values, respectively, and $T C D_{\mathrm{H}}$ increased only $14.27 \%$.

Flavour retention is higher at $-12{ }^{\circ} \mathrm{C}$, than at the previous temperatures. Green beans retained $29.63 \%$ of its initial flavour at the 14th day of storage, which makes this quality parameter still sensitive at this storage temperature.

The temperature of $-12{ }^{\circ} \mathrm{C}$ is supported by the majority of combined refrigerators, which are the most widely used on a daily basis. Thus, frozen green beans stored inside these compartments are very sensitive in terms of AA retention, with a moderate retention of total vitamin $\mathrm{C}$, limiting the nutritional quality preservation at this temperature.

\section{Quality losses at $-18^{\circ} \mathrm{C}$}

Fig. 5 presents the quality profile at $-18{ }^{\circ} \mathrm{C}$, during $15,30,45$ and 60 days of storage.
AA falls to $10 \%$ of its initial value in the first 15 days of storage. Thereafter, only residual values $(<1 \%)$ are maintained until the end of the simulated storage. AA is totally converted to DHAA in the first month of storage time. DHAA is lost at a slower rate, consequently in the first month of storage $46 \%$ of total vitamin $\mathrm{C}$ is retained, and at the end of 60 days, $21.23 \%$ retention is obtained.

Starch degradation is extensive at $-18{ }^{\circ} \mathrm{C}$. During the first 15 days, starch content decreases to $24.87 \%$ of its initial content, and attains very low values at the end of the recommended maximum storage time $(<1 \%)$. Thus, almost all starch is converted into reducing sugars, due to hydrolysis, leading to an increase in sweetness and softening. Stress at the failure point decreases to values near by the residual texture value (see Table 1). Texture retention is severely affected, with average retentions of $66.96 \%$ at end of the first month, and $56.02 \%$ at the 60 th day of storage.

Chlorophylls $a$ and $b$ are also sensitive at this temperature. Retentions are of $10.96 \%$ and $10.82 \%$, respectively, for chlorophylls $a$ and $b$ at the 60th day of storage time. Nevertheless, colour is well retained. Average retentions are $90.26 \%$ and $85.58 \%$ for Hunter $a$ and $b$ values, respectively. The $T C D_{\mathrm{H}}$ increased $14.43 \%$ at 45 days of storage (almost equivalent to 14 days at $-12{ }^{\circ} \mathrm{C}$ ) and $18.75 \%$ at the 60 th day.

Flavour retention is enhanced by low storage temperatures. Average retentions are within 48.16\%, 33.43\% and $23.22 \%$, respectively at the 30,45 and 60 days of storage. Flavour is not a shelf-life limiting factor, at the temperature of $-18{ }^{\circ} \mathrm{C}$.

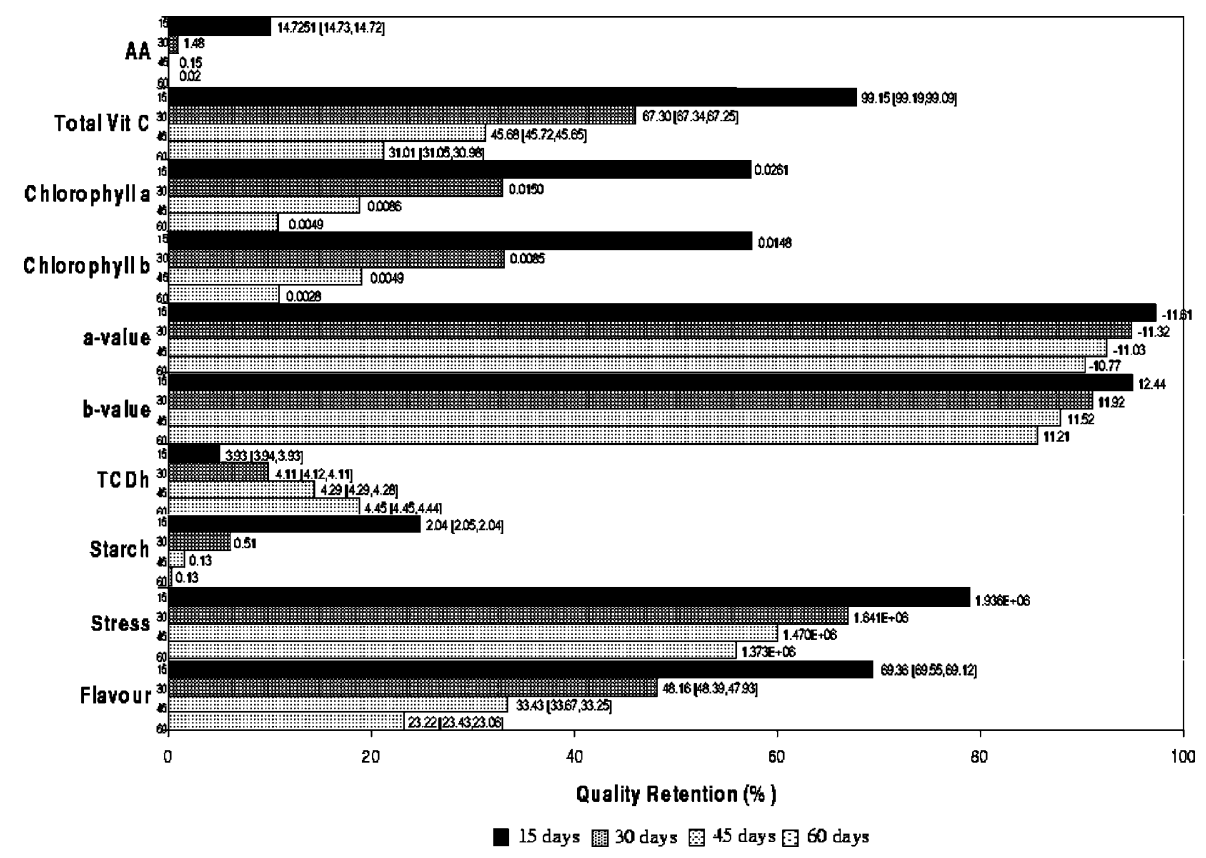

Fig. 5. Green beans quality retention (\%) profile, for $15,30,45$ and 60 days of storage at $-18{ }^{\circ} \mathrm{C}$. Maximum and minimum limits of the quality parameter average retentions are indicated between brackets, if a significant difference is registered. 
At $-18{ }^{\circ} \mathrm{C}$ starch and vitamin $\mathrm{C}$ are shelf-life limiting factors. High quality retention is obtained in the first 15 days of storage, and until the 45th day of storage good retention is obtained in nutritional terms, and the product should preferably be consumed before this date. At the recommended maximum storage time, sensory parameters are well retained, whereas, nutritional parameters are degraded (see Fig. 5).

\section{Conclusions}

Simulations demonstrate that in frozen green beans nutritional parameters are generally more sensitive to frozen storage than sensory attributes, such as colour, texture and flavour. Nutritional attributes limit the shelf-life at the lower storage temperatures. Phenomena such as starch hydrolysis and AA auto-oxidation are not significantly constrained by the low storage temperatures.

Sensory properties are well retained at low temperatures, but are very sensitive to the higher storage temperatures. For example, flavour retention has shown to be always the limiting factor of shelf-life at $+5,-6$ and $-12{ }^{\circ} \mathrm{C}$.

The recommended shelf-life dates, by the 'star marking' system, exhibit a well balanced retention of both nutritional and sensory parameters at the storage temperatures of $+5,-6$ and $-12{ }^{\circ} \mathrm{C}$, for frozen green beans. At the storage temperature of $-18{ }^{\circ} \mathrm{C}$, sensory attributes are well retained, but nutritional parameters reach residual values at the end of the 60 days. At this storage temperature, high quality retentions of both sensory and nutritional attributes are obtained before the first month of storage, and well balanced between sensory/nutritional attributes until the 45th day of storage.

The shelf-life determination is mostly influenced by the quality parameters sensitivity to temperature. Sensory properties, such as flavour and colour $\left(T C D_{\mathrm{H}}\right)$, present a high $E a$, therefore, are very temperature sensitive. These parameters are well retained at low temperatures (e.g. $-18{ }^{\circ} \mathrm{C}$ ), but unfortunately are very sensitive at the higher storage temperatures (e.g. -12 , -6 , and $+5^{\circ} \mathrm{C}$ ). Nutritional parameters (such as AA and total vitamin $\mathrm{C}$ ) exhibit low $E a$, and therefore the degradation rate is less sensitive to temperature. Frozen stored green beans at low temperature can exhibit good appearance during long storage times, however, they do not present excellent nutritional retention. At these storage temperatures, storage periods higher than 60 days produces exorbitant nutritional quality degradation. Thus, shelf-life determination of frozen vegetables should be done not only considering sensory attributes (by using a sensory panel), but also by evaluating the nutritional quality of frozen vegetables, in order to establish more well balanced shelf-life dates.

\section{Acknowledgements}

The author Martins, R.C. gratefully acknowledges his PhD grant, PRAXIS XXI BD/18541/98, to the Fundação para a Ciência e Tecnologia (FCT).

\section{References}

Alonso, J., Canet, W., \& Rodrigez, T. (1997). Thermal and calcium pre-treatment affects texture, pectinesterase and pectic substances of frozen sweet cherries. Journal of Food Science, 62, 511515.

Braess, D. (1997). Finite elements theory, fast solvers, and applications in solid mechanics. Cambridge: Cambridge University Press.

Byers, T., \& Perry, G. (1992). Dietary carotenes, vitamin C and vitamin E as protective antioxidants in human cancers. Annual Reviews in Nutrition, 12, 139-159.

Dietrich, W. C., Boogs, M. M., Nutting, M. D., \& Weinstein, N. E. (1960). Time temperature tolerance of frozen foods xxiv: quality changes in cauliflower. Food Technology, 14, 123-128.

DrLange (1994). Colour review. DrLange application report No. 8e. DrLange, USA.

DrLange (1999). Fundamentals of colorimetry-application report No. 10e. DrLange, USA.

Fuchigami, M., Hyakumoto, N., \& MiYazaki, K. (1995). Programmed freezing affects texture, pectic composition and electron microscopic structures of carrots. Journal of Food Science, 60, $137-$ 141.

Heaton, J. W., Lencki, R. W., \& Maragoni, A. G. (1996). Kinetic model for chlorophyll degradation in green tissue. Journal of Agricultural and Food Chemistry, 44, 399-402.

Jackman, R. L., \& Stanley, D. W. (1995). Perspectives in the textural evaluation of plant foods. Trends in Food Science \& Technology, 6, 187-194.

Labuza, T. (1982). Shelf-life dating of foods. Wesport, Connecticut: Food \& Nutrition Press.

Martins, R.C. (2003). Modelling temperature abuses to frozen foods and effects on quality. PhD Thesis, Escola Superior de Biotecnologia, Universidade Católica Portuguesa, Porto, Portugal.

Martins, R. C., \& Silva, C. L. M. (2002). Modelling colour and chlorophyll's losses of frozen green beans (Phaseolus vulgaris, L.). International Journal of Refrigeration, 25, 987-995.

Martins, R. C., \& Silva, C. L. M. (2003). Kinetics of frozen stored green beans (Phaseolus vulgaris, L.) quality changes: texture, vitamin $\mathrm{C}$, reducing sugars and starch. Journal of Food Science, 68(7), 2232-2237.

Moharram, Y., \& Rofael, S. (1993). Shelf-life of frozen vegetables. In G. Charlambous (Ed.), Shelf life studies of foods and beverageschemical, biological, physical and nutritional (pp. 243-253). Amsterdam: North-Holland Elsevier.

Montegomery, D. (1991). Design and analysis of experiments (3rd ed.). Singapore: John Wiley \& Sons.

Ramaswamy, H. S., \& Tung, M. A. (1981). Thermo-physical properties of apples in relation to freezing. Journal of Food Science, 46, 724-728.

Schwartz, S. J., \& Von Elbe, J. H. (1983). Kinetics of chlorophyll degradation to pyropheophytin in vegetables. Journal of Food Science, 48, 1303-1306.

Schwartzberg, H. G. (1976). Effective heat capacities for freezing and thawing of food. Journal of Food Science, 41, 153.

Segerlind, L. (1984). Applied finite element analysis (2nd ed.). New York: Macmillan Press, LTD.

Tong, H. (1994). Non-linear time series: a dynamical system approach. New York: Oxford University Press. 